\title{
AS PAISAGENS DA TRANSIÇÃO ENERGÉTICA: UMA PERSPECTIVA POLÍTICA ${ }^{1}$
}

\author{
THE LANDSCAPES OF ENERGY TRANSITION: A POLITICAL \\ PERSPECTIVE
}

\author{
Marie-José Fortin \\ Université du Québec à Rimouski - Rimouski - Québec - Canadá
}

\begin{abstract}
Resumo: Além de grandes objetivos genéricos, a transição energética necessita ser traduzida em políticas e em projetos bastante concretos. A implementação destes últimos, frequentemente na forma de amplos sítios de produção de energia, provoca fortes reações nos territórios, entre outros, em nome da paisagem. Entretanto, ao invés de reconhecer nesse fato uma reação sistemática de oposição, sugere-se considerar a paisagem enquanto uma forma de testar o nível de territorialização das propostas realizadas em nome da transição energética: na qualidade de arcabouço cognitivo e político, a paisagem permitiria, deste modo, confrontar "projeto" e "território", e compreender se o primeiro demonstra-se coerente e representativo em relação ao futuro do segundo. Nesse sentido, propõe-se um roteiro de análise estruturado em três níveis, referindo-se a abordagens teóricas complementares, quais sejam: a paisagem 1) como representação social, 2) como instrumento e objeto negociado e 3) como paradigma societal. $O$ recente desenvolvimento da matriz eólica no Québec ilustra como a "paisagem" poderia ser mobilizada nesse sentido.
\end{abstract}

Palavras-chave: Paisagem política. Energia. Energia eólica. Territorialização. Aceitabilidade social.

Abstract: Beyond major general objectives, energy transition needs to be translated into concrete policies and projects. The implementation of such policies and projects, often in the form of large sites for the generation of energy, gives rise to strong reactions, notably in defence of the landscape. But rather than interpret this as a reaction of systematic opposition, we propose to consider the landscape as a way of testing the level of territorialisation of proposals made in the name of the energy transition. As a cognitive and political framework, this makes it possible to compare the project with the territory and to understand whether the former is consistent with and able to provide perspectives for the future of the latter. To do so, we propose an analytical framework structured on three levels referring to complementary theoretical approaches: the landscape 1) as a social representation, 2) as a tool and a negotiated object, 3) and as a societal paradigm. The recent wind energy sector in Quebec serves to illustrate how the «landscape» could be mobilised in such a way.

Keywords : Political landscape. Energy. Wind. Territorialisation. Social acceptability.

\footnotetext{
${ }^{1}$ Este artigo provém de diversos trabalhos realizados ao longo dos últimos dez anos sobre as paisagens de produção industrial ou energética, individualmente ou com colegas, aos quais nós agradecemos : Sophie Le Floch, Anne-Sophie Devanne e, especialmente, Yann Fournis, que comentou judiciosamente e enriqueceu a primeira versão deste artigo. Nós citamos aqui, alguns resultados gerais que apoiam nossa demonstração, referindo-nos às publicações em que foram originalmente apresentados. Este artigo foi publicado originalmente em francês com o título "Les paysages de la transition énergétique : une perspective politique", no dossiê temático "Le paysage à l'épreuve de la transition énérgetique" da revista eletrônica Projets de paysage número 10, lançado em 2014. Nós agradecemos aos editores por terem autorizado a presente publicação.
} 


\section{INTRODUÇÃO: A PAISAGEM POLÍTICA, UMA AMEAÇA PARA A TRANSIÇÃO?}

A transição energética traz consigo uma vasta ambição: a reorientação dos modos de produção e de consumo de energia. Entretanto, sua realização por meio da implementação de grandes sítios de produção, provoca fortes reações nos territórios, onde se concretizam e se revelam os impactos despercebidos ou negligenciados que afetam o cotidiano e as condições de vida das populações locais, ocasionando reações de crítica ou de recusa. Este é o caso dos parques eólicos, palcos de divergências mantidas em várias regiões do mundo em nome da paisagem.

Longe da síndrome "não em meu quintal" (NIMBY), ou dos impactos visuais apenas, o discurso em torno da paisagem revela, por meio de sua variedade, várias exigências societais contemporâneas sobre a maneira de conceber, de planejar e de implantar projetos, políticas e modelos de produção de energia. Aí encontra-se, em hipótese, a possibilidade de superação da oposição estéril entre as contestações e os atuais megaprojetos setoriais, para construir verdadeiros projetos de territórios. A questão fundamental é a territorialização da transição energética: as políticas e o projeto de produção de energia (incluindo suas infraestruturas de grande porte) não podem se contentar em serem genéricos, passando por uma implementação livre de um trabalho mínimo de tradução e de adaptação à realidade dos lugares de implantação (Évrard, 2010). Esse trabalho de estabelecimento de ligações com as sociedades territoriais e suas trajetórias é exigente, pois suscetível de contestar muitos aspectos do projeto (natureza, tamanho, localização, modo de propriedade, etc.), se os mesmos foram concebidos de modo genérico e com parâmetros a-territoriais (mercado, técnica...).

Este artigo sugere recorrer ao conceito de paisagem enquanto um esquema de análise global para testar, cognitivamente e politicamente, o grau de territorialização de um projeto de produção de energia. O recente exemplo da matriz eólica no Québec demonstra como a "paisagem" poderia ser mobilizada nesse sentido por meio de três abordagens teóricas complementares, quais sejam: a paisagem 1) como representação social, 2) como instrumento e objeto negociado e 3) como paradigma societal ${ }^{2}$. Essas três abordagens convergem para uma necessária consideração da dimensão política da paisagem, segundo uma proposta testada anteriormente em outros tipos de paisagens produtivas (Fortin, 2005; Fortin e Gagnon, 2006) e que une-se a outros trabalhos sobre a noção de aceitabilidade social (Fortin e Fournis, em revisão ; Fournis e Fortin, 2014). Enfim, a proposta visa reforçar os trabalhos associados ao paradigma político da paisagem, o qual, embora emergente há uma dezena de anos (Fortin, 2005), começa a ser evidenciado ${ }^{3}$, e relacioná-los com aqueles já bem estruturados associados ao paradigma cultural.

\footnotetext{
${ }^{2}$ Este roteiro também pode ser aplicado a outros tipos de projetos de produção de energia (centrais hidroelétricas, portos de gás natural GNL) que enfrentam regularmente oposição local, e mesmo nacional, em que os procedimentos formais de avaliação penam a responder.

${ }^{3}$ Ver, entre outros, exemplares de revistas (por exemplo, Landscape Research, Vol. 32, $n^{\circ} 5$; revue Développement durable et territoire, Vol. 1, $\mathrm{n}^{\circ} 2$ | Septembre 2010), ou de títulos de obras recentes (Bédard, 2009; Paquet et Mercier, 2013).
} 
Nesse sentido, iniciaremos este artigo esboçando um diagnóstico do setor energético no Québec, o qual sugere que a implementação da transição energética exige, necessariamente, uma forma de contextualização, de territorialização.

\section{JUSTIFICANDO A TRANSIÇÃO NO CONTEXTO DAS ENERGIAS RENOVÁVEIS: O CASO QUEBEQUENSE}

Aparentemente, o Québec ocupa uma posição privilegiada para enfrentar os desafios da transição energética. Localizado em um vasto território onde os recursos naturais são abundantes, a "bela província" extrai até 95\% de sua produção de eletricidade de fontes renováveis, principalmente a energia hidroelétrica, seguida da energia eólica ${ }^{4}$. A fonte hidráulica, valorizada pela empresa estatal Hydro-Québec há mais de 50 anos, constitui um ativo e um patrimônio reconhecidos: o Estado é proprietário de uma vasta rede de grandes reservatórios e centrais hidroelétricas, sendo o quarto maior grande produtor mundial de hidroenergia depois da China, do Brasil e dos Estados Unidos ${ }^{5}$ (com uma capacidade de produção instalada de mais de $37000 \mathrm{MW}^{6}$ ).

Esses primeiros dados falam por si: a transição energética lança desafios ao Québec diferentes dos enfrentados pelos países europeus, na medida em que a escolha do setor eólico não se explica nem pela forte demanda de energia, nem pela necessidade de liberar-se das energias não renováveis. A escolha da matriz eólica se enquadra no acoplamento entre economia (desenvolvimento regional) e energia (desenvolvimento da matriz eólica). Embora esta acoplagem se dê em continuidade com políticas anteriores, ela é nova em virtude de sua aspiração: a implantação de um verdadeiro setor industrial ligado à energia eólica, afim de diversificar a frágil economia de uma região, a Gaspésie.

Após a realização de diferentes etapas de teste ${ }^{7}$, a política de produção da energia eólica é efetivamente lançada no início dos anos 2000, sendo favorecida por um contexto em que os diferentes interesses de atores sociais convergem ${ }^{8}$. Dentre os instrumentos dessa política, o sistema de concurso público (chamada de projetos) é certamente o mais conhecido. Ele coloca em concorrência promotores,

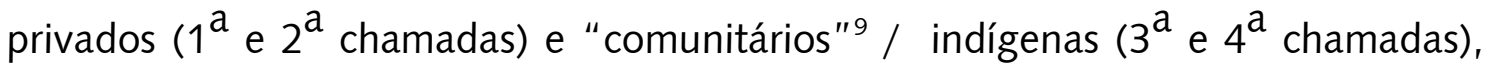

\footnotetext{
${ }^{4}$ Fonte : http://mrn.gouv.qc.ca/energie/statistiques/statistiques-production-centrales.jsp consultée le 16 octobre 2013.

${ }^{5}$ Fonte : idem.

${ }^{6}$ Fonte: http://hydroforthefuture.com/projets, consultado em 1 de jullho de 2012.

${ }^{7}$ Após as primeiras tentativas tecnológicas realizadas em 1987 em torno da turbina eólica de eixo vertical Éole, na costa norte da península de Gaspé (em Cap-Chat), o primeiro grande parque de capacidade de 100 MW, o Nordais, entrou em operação em 1998.

${ }^{8}$ Embora continue a ser difícil de explicitar as razões formais que motivam a inserção de um novo item na agenda das políticas públicas, pressupostos podem ser ao menos avançados. No caso da energia eólica, notemos que os interesses de muitos grupos de atores sociais convergem em um curto período, favorecendo o alinhamento das estratégias, em especial a mobilização de grandes ONG ambientais para impulsionar o setor eólico, a reivindicação de uma elite gaspesiana de investimento no setor e a contestação social do projeto da central térmica de Suroît.

${ }^{9}$ O termo "comunitário" é o termo oficialmente empregado na licitação de projetos. Refere-se mais especificamente à implicação de coletividades locais (municípios ou MRC) no financiamento e na propriedade de um sítio de produção de energia eólica, da ordem de pelo menos $30 \% \mathrm{em}$ parceria com uma empresa privada.
} 
os quais devem submeter projetos de parques eólicos, respeitando uma série de critérios (em especial, a exigência de uma porcentagem significativa dos benefícios econômicos da construção e da montagem dos parques eólicos no território da península gaspesiana e da entidade administrativa infrarregional, em francês Municipalité régionale de compté - MRC, de Matane).

Os objetivos econômicos (criação de empregos e diversificação da economia), considerados louváveis, não geraram críticas e são apoiados por um grande número de grupos regionais. Entretanto, a fórmula adotada nos concursos tem efeitos bastante drásticos: para atrair esses parques, é preciso estimular uma forte demanda interior (ou até mesmo um comércio de proximidade), o que neste caso, traduziu-se finalmente numa implantação acelerada de cerca de 40 grandes parques eólicos no Québec (totalizando $4000 \mathrm{MW}$ de capacidade instalada para parques de 30 a 70 turbinas - mas de até 150 turbinas em dois casos mais recentes - com altura superior a 100 metros $^{10}$ ), cuja metade se concentra no leste desta província. Na medida em que esses projetos tomam forma, perguntas e críticas surgem dos territórios em questão, primeiramente na região do Bas-Saint-Laurent, a partir de 2006, depois em outras regiões. Nesse contexto, examinar-se-á as perguntas e críticas relacionadas à paisagem a partir de três prismas (abordagens) complementares, mostrando assim, como o desafio da territorialização desses megaprojetos exógenos se situa simultaneamente em diversos níveis.

\section{DEFININDO AS QUESTÕES: O PRISMA DAS REPRESENTAÇÕES PAISAGÍSTICAS}

De maneira geral, a contestação dos parques eólicos tem má fama, sendo comumente caricaturada como a síndrome "não no meu quintal" (NIMBY). Essa leitura simplista serve para banalizar certas reivindicações e importantes questões, incluindo aquelas relativas à paisagem. Após análises estatísticas, Wolsink (2000, p. 51) conclui, entretanto, que os efeitos percebidos na paisagem constituem o "melhor indicador para prever a atitude" positiva ou negativa em relação a um parque eólico ${ }^{11}$. Dito isso, há muito o que fazer: a paisagem continua muito menos conhecida do que se parece. A análise das representações sociais oferece uma maneira de abrir essa caixa preta.

A perspectiva das representações das paisagens mergulha suas raízes na geografia francesa dos anos 1970, quando uma primeira geração de trabalhos procura "reconstruir o status dos lugares" (Bailly, 1984, p. 138, tradução nossa), com o auxílio, em especial, de conceitos de imagens e mapas mentais ${ }^{12}$. Uma nova geração surge nos anos 1990, dessa vez, em reação a certas proposições

\footnotetext{
${ }^{10} \mathrm{Na}$ verdade, 12 parques são de um tamanho mais modesto (8 a 12 turbinas eólicas). Trata-se de parques provenientes das três (3) chamadas de projetos "comunitários" (www.mrn.gouv.qc.ca/energie/eolien/eolien-potentiel-projets.jsp, consultado em 11 de março de 2013).

11 " The strongest impact on the attitudes concerned the aesthetic value of wind turbines. The perceived impact on scenery, visual intrusion of the landscape as well as positive judgements, is the best predictor of the attitude » (Wolsink, 2000, p. 51).

$12 \mathrm{Em}$ uma perspective similar, Donald Meining (The interpretation of the ordinary landscape, 1979), Yi-Fu Tuan (Topophilia) e Edward Relph (Place and Placelessness, 1976) proprocionaram contribuições reconhecidas do lado anglo-saxão que continuam os trabalhos de J B Jackson (Creswell, 2003, p. 271).
} 
associadas à paisagem-cênica (ver a "Missão etnológica sobre paisagem" ; Dubost et Lizet, 1995). Desde então, os trabalhos de cunho geográfico, sociológico e antropológicos são abundantes (em especial, em torno dos programas de pesquisa "paisagem e desenvolvimento sustentável" ${ }^{13}$, Terrasson et al., 2007; Luginbühl et Terrasson, 2013).

Os proponentes desta perspectiva (a paisagem como representação social) se opõem à ideia de uma cultura da paisagem universal baseada unicamente em grandes referenciais, como os artísticos, de mídia e os turísticos. Eles sustentam que a cultura da paisagem provém igualmente de fatores mais específicos, ligados às características singulares das trajetórias individuais e coletivas e às dinâmicas socioterritoriais. Nesse sentido, as práticas territoriais, a vivência (lembranças, história de vida), os mitos e as crenças das pessoas e dos grupos constituiriam filtros potenciais intervindo entre o sujeito e o objeto na construção da paisagem. Esse duplo alicerce, em referenciais universais e outros locais e singulares, conduz, assim, a análise a reconsiderar os contextos geográfico, social e histórico.

Essa pista parece proveitosa na área de produção energética, em que uma parte do choque global/local se explica pela concepção "genérica" dos projetos, frequentemente exógenos e de envergadura imponente, abrindo-se pouco às particularidades e dinâmicas do território de acolhimento. A análise permitiria, assim, revelar as particularidades do território e das sociedades que o habitam. Essa é a pista seguida em um estudo das respostas a dois projetos de parques eólicos na Gaspésie (Fortin et LeFloch, 2010). A análise de 30 relatórios apresentados nas audiências públicas regidas pelo $\mathrm{BAPE}^{14}$ revelou rapidamente que as reivindicações efetuadas não são unidas nem homogêneas. Há muitas demandas sociais sobre a paisagem, levantando diferentes questões, as quais podem ser classificadas em quatro grupos, referindo-se às diferentes concepções da paisagem.

O primeiro grupo $\left(n^{\circ} 1\right)$, proveniente sobretudo do mundo econômico (privado ou institucional), silencia-se sobre a questão. A matriz eólica é um componente de um parque de produção de energia que, por si só, conquista espaço em um setor fortemente almejado na região em virtude dos seus benefícios econômicos. Nesse ponto de vista, a questão principal está associada à distribuição socioespacial dos benefícios da exploração do recurso eólico (por exemplo: qual município se beneficiará dos empregos criados pelas usinas de montagem ?).

Para os três outros grupos, as dimensões cênicas da paisagem são mais importantes, mas a diferente ênfase dada à subjetividade da experiência da paisagem corresponde de fato a três concepções de paisagem. Para o grupo $n^{\circ} 2$, o debate gira em torno da concepção clássica da "bela paisagem", associada à contemplação visual de um espaço onde as formas respondem aos cânones da

\footnotetext{
${ }^{13} \mathrm{O}$ programa PDD foi lançado pelo ministério francês encarregado do meio ambiente e precedeu o programa Políticas Públicas e Paisagem.

${ }^{14}$ O Escritório de Audiências Públicas sobre o Meio Ambiente (em francês, Bureau des audiences publiques sur l'environnement - BAPE) é um órgão público subordinado ao Ministério do Desenvolvimento Sustentável, do Meio Ambiente e da Luta contra as Mudanças Climáticas. No contexto do procedimento de avaliação ambiental, ele "informa, investiga e consulta a população sobre os projetos e as questões relativas à qualidade do meio ambiente, a qual ele submete ao ministro. Ele produz em seguida os relatórios da investigação colocados à disposição do público. $O$ BAPE é consequentemente um órgão governamental de consulta e não de decisão." (extraído de http://www.bape.gouv.qc.ca/sections/bape/organisme/index.htm, consultado no dia 8 de junho de 2014, tradução nossa).
} 
cultura paisagística em vigor. Metodologicamente, essa concepção é preocupante, pois difícil de avaliar ou discutir. Raras, as referências ao registro atual do "belo" ou do "harmonioso" são substituídas por um vocabulário que se diz mais neutro, evocando a "integração" ou a "alteração" e visando controlar melhor os impactos visuais de um projeto. Entretanto, essa postura revela um paradoxo: a dificuldade de "camuflar" essas imensas estruturas de produção de energia eólica, que excedem em muito os cumes das florestas, conduz rapidamente ao reconhecimento de impotência e à relativização da questão da paisagem, apresentada, no entanto como secundária em relação aos outros ganhos da construção dos parques. E ainda, a questão se modifica aproximando-se daquela evidenciada pelo grupo precedente: trata-se do domínio das infraestruturas associadas ao setor industrial, de modo que as comunidades locais se apropriem plenamente dos recursos eólicos, sob a forma de um recurso "específico" enraizado no território.

Para os dois últimos grupos, a subjetividade da relação com a paisagem é, ao contrário, constitutiva da experiência da paisagem e deve ser reconhecida (e discutida) como um fator determinante da tomada de decisão no que concerne à concepção dos parques eólicos. Nesse sentido, a paisagem deveria ser considerada desde o início do processo, por meio de novas abordagens e estratégias ligando paisagem e ordenamento do território. Entretanto, é nesse nível que aparecem as divergências entre os dois grupos que defendem as concepções diversificadas da paisagem, as quais impulsionam a formulação de questões de forma diferente. Para alguns (grupo $n^{\circ} 3$ ), a paisagem é um recurso para a indústria turística ou para a atratividade das localidades e toda a questão é de assegurar sua cohabitação com a indústria eólica. Para outros (grupo $n^{\circ} 4$ ), mais ambiciosos, a concepção de paisagem é política e sua questão é o reconhecimento, nas escolhas e práticas de governança dos recursos naturais, do papel das paisagens nas necessidades culturais das populações locais (identidade, qualidade de vida).

Enfim, salienta-se a contribuição desse primeiro prisma de leitura da paisagem, centrado nas representações sociais. A análise revela rapidamente que as posições expressas nos conflitos não são binárias (defensores/adversários da energia eólica), mas que, na verdade, se baseiam em concepções diferentes da paisagem, as quais se articulam em função de dois sistemas de representações do território (território de produção/paisagem habitada) e revelam muitas questões. Estas últimas não podem assim serem reduzidas em questões de proximidade (incômodos visuais e sonoros) pois elas encarnam perguntas fundamentais que, assim como a governança territorial e a justiça social, implicam a determinação do destino dos territórios em questão (por exemplo, "por que estes grandes projetos? Para quem? Em benefício de quem? E, sobretudo, em prejuízo de quem?).

Em suma, pensar seriamente a transição energética exigirá não esquivar-se dos parâmetros que determinam a qualidade dos territórios e os requisitos que os tornam habitáveis (condições e qualidade de vida, bem-estar e melhor-estar, identidade, relações sociais, etc.). Essas questões são importantes, pois afetam necessidades cruciais dos habitantes, e exigem respostas também importantes, capazes de nutrir os compromissos fundadores da aceitabilidade social dos parques eólicos e, mais amplamente, da transição energética. Com esse objetivo, duas outras perspectivas podem contribuir a nutrir a reflexão, começando pela paisagem como instrumento de mediação e de negociação. 


\section{INICIANDO O DEBATE : PERSPECTIVA DA PAISAGEM COMO INSTRUMENTO NEGOCIADO}

A reivindicação de uma forte implicação das populações locais está no centro das disputas sobre os projetos de produção de energia. Ele ressoa também nos trabalhos emergentes, em especial na França, provenientes de uma rede de pesquisadores ativos no desenvolvimento local e territorial. Seguindo os esforços pioneiros de Y Michelin (2001), que confiava aparelhos fotográficos aos habitantes, os escritos de Lelli et Paradis (2005), de Debardieux et Lardon (2003) visam dar a palavra aos habitantes pelo intermédio da cartografia e de outros tipos de simulação visual. A dimensão aplicada desses trabalhos, até então pouco presente, permite conceber e testar abordagens e instrumentos focados na paisagem para acompanhar os atores do desenvolvimento. A "paisageminstrumento" torna-se assim um objeto de mediação social, "um meio para construir uma cultura comum" em um processo de co-construção do território (Davodeau, 2009, p. 6, tradução nossa) que abranja tanto a forma da paisagem quanto os referenciais que fundamentam sua essência (Derioz, 2012; Guisepelli et al., 2013).

Essa perspectiva de paisagem-instrumento, situada no âmago de uma negociação social, refere-se ao debate simultâneo sobre o projeto e as qualidades do território. Recuperada pelos atores quebequenses do setor público, ela foi inscrita nas propostas de planejamento territorial, as quais, mesmo sem retomar os instrumentos anteriores, podem ser associadas a esta abordagem de paisagem. Em 2007, o Ministério responsável do ordenamento do território no Québec (MAMR) certamente fez a proposta mais inovadora.

A paisagem-instrumento possui muitas rupturas com as práticas tradicionais em paisagem (Fortin et al., 2010). De forma geral, essa abordagem de planejamento foca na participação de uma diversidade de atores para determinar os territórios suscetíveis (ou não) de acolher parques eólicos em uma espécie de amplo zoneamento. Trata-se de uma importante inversão das práticas usuais, pois a responsabilidade de avaliação passaria das mãos dos especialistas àquelas das populações locais, convidadas a participar de diferentes etapas (principalmente da caracterização e da avaliação da qualidade das paisagens) pois consideradas como detentoras de um conhecimento específico e de um direito legítimo de fazerem parte das decisões que afetam seu território de vida.

Em virtude de seus objetivos, essa abordagem atende não somente às fortes demandas sociais de participação expressadas durante os conflitos, mas se insere de maneira mais abrangente nas novas modalidades de construção da paisagem valorizadas pelas políticas públicas mais recentes, em conformidade com o espírito da Convenção Europeia da Paisagem (Jones, 2007) e próximo aos princípios de outras experiências estrangeiras ${ }^{15}$. Entretanto, embora detentora de todas essas qualidades, a abordagem do Ministério não é aplicada. A difícil passagem à prática pode se explicar por diversos fatores, como o atraso da proposta (vários projetos já estavam autorizados; mas outros eram esperados).

\footnotetext{
${ }^{15}$ Pensemos aqui nos padrões de parques eólicos realizados na França. Certamente, sua concepção é restrita unicamente ao círculo de autoridades locais, excluindo a participação dos habitantes no debate. Mas, ainda assim, nota-se um deslocamento do nível da governança, levando-se em consideração o território para se estabelecer o planejamento espacial da matriz.
} 
Todavia, o desafio se situa muito além disso, tal como no desconforto ligado ao "risco" dos debates sobre a paisagem, que revelam rapidamente a sociodiversidade das comunidades territoriais (Fortin, Devanne et LeFloch, 2010). $\mathrm{Na}$ verdade, as abordagens evidenciam as diferenças entre os pontos de vista sobre as paisagens locais, tanto dos habitantes quanto dos outros atores tais como as associações ambientais (conforme "green on green debate", Warren et al., 2005). Surge, em seguida, o problema de decidir entre as opções apresentadas e, sobretudo, de avaliá-las: quais pesos atribuir às respectivas expectativas e necessidades na tomada de decisão? Como construir o interesse geral e uma decisão legítima?

A dificuldade deste tipo de planejamento deliberativo ligado à paisagem conduz ao retorno do uso de instrumentos tradicionais (estudos especialistas, marcos regulamentares locais - e muitos outros, especialmente quando esses possuem caráter jurídico obrigatório). Essa é a lição do caso do Município de Sainte-Luce, na região do Bas-Saint-Laurent, onde a pressão dos adversários impulsiona as autoridades locais a propor regulamentos de zoneamento provisórios (Fournis et al., 2013). Essa orientação delimita o debate com vistas a um referendo, de maneira ambivalente: se cada habitante exerce individualmente um poder de decisão, este último exige um posicionamento simplista ("a favor" / "contra"). Isso multiplica as tensões na comunidade e, ao fechar o espaço de deliberação, proíbe outras possibilidades de reconstrução do projeto e bloqueia o processo de negociação. Esse caso ilustra também a pouca margem de manobra das coletividades locais quanto aos projetos de produção de energia: em virtude das regras fixadas pelo Estado central, a discussão e a decisão local se concentra apenas na localização destes grandes sítios (aqui ou lá ?), sem autorizar perguntas sobre a sua relevância (é desejável ?). A negociação bastante limitada destes projetos faz do conflito a única alternativa possível para os grupos que desejam defender exigências importantes. Na verdade, essa necessária discussão sobre os grandes parâmetros que fixam os projetos refere-se ao terceiro nível do roteiro de análise proposto, apresentado a seguir.

\section{O AJUSTAMENTO DOS MODELOS HERDADOS SOB TENSÃO : A PAISAGEM COMO PARADIGMA SOCIETAL}

Uma outra concepção de paisagem completa o roteiro analítico proposto, referindo-se aos parâmetros de escala "macro", estruturados em longas temporalidades e reunidos sob a expressão do "paradigma societal". O interesse nessa questão, tal como praticada notadamente em alguns trabalhos da teoria da Regulação, é considerar simultaneamente o peso das variáveis consideradas (trajetórias econômicas, grandes arranjos políticos, etc.) e o lugar dos atores e projetos alternativos ("grandes" atores, novos movimentos sociais), lembrando o papel do político e das lutas entre grupos visando a influenciar o rumo da sociedade ("paradigma societal") (Lipietz, 1994). Essa perspectiva tem, em particular, o interesse de não separar as "velhas" críticas estruturais do capitalismo dessas "novas" críticas, mais simbólicas e culturais, mas de associá-las como duas faces de uma mesma transformação da sociedade, cujas lutas simbólicas (em torno 
da "hegemonia") estão no centro da decomposição de estruturas do fordismo (sobre o Canadá : Jenson, 1989).

Concretamente, no caso da paisagem, esse tipo de abordagem traz uma contribuição concreta ao seu paradigma político, ainda emergente. Até certo ponto, eles estendem o paradigma cultural da paisagem, reconhecendo as dimensões socialmente construídas da mesma, em que a ideia de "belo" não é inata, e sim adquirida, socialmente, historicamente (Greider et Garkovich, 1994). Acrescentam, no entanto, uma perspectiva decididamente crítica ou estruturalista, segundo os autores. Situa-se resumidamente, alguns pontos de referência e fundamentos desta literatura, muitas vezes pouco explorada, antes de examinar sua contribuição aos debates sobre o setor energético.

Em meados dos anos 1980, Denis Cosgrove (1998) acrescenta uma peça fundamental aos estudos sobre a paisagem, propondo o reposicionamento dos mesmos, o qual combinaria as perspectivas humanista e marxista. Como paradigma cultural, essa posição insiste na experiência visual que comporta a paisagem e demonstra como esta é uma "maneira de ver", culturalmente e historicamente situada, a qual provém de uma relação social específica ao território. No entanto, o autor insiste igualmente sobre a ideia de que a paisagem não é um "negócio moralmente ou politicamente neutro" (2003, p. 257, tradução nossa), sustentando que a cultura é uma questão de luta das classes: a paisagem tem um papel de regulação social, tal como uma maneira de ver a "concretude" dos territórios ou tal como um olhar cultural normalizando e banalizando os processos em andamento. Este último, refere-se à concepção dialética da paisagem defendida por Paul Vidal, de la Blache e Carl Sauer, ligando objeto e sujeito, materialidade e simbolismo, acrescentando, porém, a dimensão da classe (Cosgrove, 1983, p. 3).

Por sua vez, o americano Don Mitchell define a paisagem como "um momento complexo de um sistema de reprodução social" (1996, citado em 2003 : 240, tradução nossa). Ele ressalta o aspecto potencialmente móvel da paisagem, no sentido de que sua "permanência" é condicional à perenidade do sistema social que a produziu. A todo instante, ela pode "tornar-se um lugar de luta" e ser modificada, "pois ela é uma internalização (e concretização) de relações sociais" (Mitchell, 2003, p. 240, destaque do autor, tradução nossa). A fixidez da paisagem, dessa que é vista, seria apenas uma ilusão : "idolatrada", "mistificada", a paisagem camufla "os processos que participam de sua fabricação. E isso é justamente o seu objetivo" (Mitchell, 2003, p.241, tradução nossa). Por essa razão, torna-se necessário olhar além das formas visíveis da paisagem, como por exemplo, no caso das paisagens agrárias da Califórnia. Esses circuitos de produção agrícola de morango, os quais, num primeiro momento, estruturam as condições de vida e de trabalho de imigrantes, mas que posteriormente geram graves problemas éticos e ambientais. Sendo assim, a análise das paisagens se realiza aqui por meio de três elementos : os processos subjacentes à sua construção, as suas mudanças (evolução) e as suas repercussões.

De inspiração marxista, feminista ou regulacionista, essa corrente insiste, assim, no papel socializador da cultura e na sua dimensão "conflituosa" (Lipietz, 2000), oferecendo uma melhor compreensão dos processos sociais, econômicos e ecológicos abrangentes que modelam os territórios (Olwig et Mitchell, 2007) e se cristalizam sob a forma de sistemas mais ou menos estáveis de ideias e de 
instituições. Esses estudos valorizam as relações sociais em que esses processos se inscrevem e reproduzem. Elas mostram também as repercussões desses processos sobre os territórios e as populações (exclusão, dominação social, desigualdades sociais e ambientais) que ameaçam as comunidades e a qualidade dos territórios habitados e participam da criação de "paisagens de riscos" (Blowers, 1999).

Em matéria de produção energética, poucos estudos examinam tais processos sociais e econômicos macroestruturais que modulam as grandes paisagens, enquanto que os megaprojetos de produção de energia nascem (também) desses mesmos processos de longa temporalidade, desses importantes compromissos sociais que alimentam os modelos de desenvolvimento e de estruturação das economias. O mercado de energia atual, por exemplo, aparece marcado pela forte tendência da internacionalização, visto que a desregulamentação dos mercados nacionais autoriza a concentração dos setores de produção em torno de algumas grandes empresas detentoras da tecnologia, cujo modelo adotado favorece projetos de grande porte, defendidos por algumas corporações dominantes (hard path) (Sarka, 2007). Entretanto, esses estudos ensinam também que essa forte tendência é acompanhada de formas de resistência, ou seja, de movimentos de adaptação por parte de alguns Estados que mantêm a capacidade de influenciar a estruturação de suas economias.

Isso revaloriza alguns mecanismos adotados pelos Estados para orientar os mercados de energia (tarifa fixa, cotas, etc.) e, de maneira mais abrangente, os legados institucionais nacionais que pesam sobre as escolhas energéticas atuais (Lewis e Wiser, 2007), em especial, as escolhas do passado que, realizadas no contexto de determinados regimes de exploração de recursos, constituem trilhas de dependência (Nadaï et al., 2013). O capitalismo assume, dessa maneira, formas diferentes de acordo com os territórios, o que é evidenciado pela utilização de um ou vários modos de propriedade de infraestruturas de produção e de distribuição (privado, público, comunitário) no âmbito de trajetórias nacionais diferenciadas. $\mathrm{E}$ essas trajetórias oferecem aos atores sociais posições diferentes na definição de tais arranjos sociopolíticos - em particular com o surgimento, ao lado dos atores clássicos (Estado, grandes corporações), de protagonistas novos mas essenciais, como as coalizões locais e regionais.

Sob esse ângulo, a energia eólica no Québec se inscreve em um quadro preexistente, o setor hidroelétrico, o qual consiste em si um modelo histórico dominante, em especial no Canadá, de exploração dos recursos naturais, chamados de "recursos primários" (staples) (Netherton, 2008). No setor de produção hidroelétrica, uma primeira grande mudança se dá nos anos 1960, quando o sistema dominado pelas empresas privadas é substituído por um regime público, bastante centralizado, controlado pela empresa estatal Hydro-Québec e territorializado em grandes projetos de equipamentos (Fournis et al., 2013). Ainda dominante, esse modelo histórico passa atualmente por uma segunda mudança, atribuindo uma importância cada vez maior à empresa privada e às parcerias do tipo público-privado - mudança ligada inclusive às contestações crescentes associadas aos regimes de recursos (Howlett et Brownsey, 2007). No caso da energia eólica, essa recomposição leva atores territoriais, historicamente marginalizados, à reivindicar novas modalidades de partilha do recurso e a propor novos arranjos. 
No contexto de uma reflexão sobre o posicionamento dos recursos naturais na economia regional, a Organização Regional dos Representantes Políticos da Gaspésie e das Ilhas da Madalena, em francês Conférence régionale des élus de la Gaspésie et des îles-de-la-Madeleine (CRÉ-GîM), investiu amplamente na questão eólica como uma indústria do futuro, suscetível de compensar o declínio de indústrias tradicionais (florestal, de pesca e de mineração). Entretanto, precisou-se, ainda, impor localmente essa opção eólica, e, dessa forma, negociar sua inserção territorial de modo satisfatório para os atores regionais por meio do Regulamento intermunicipal de energia da CRÉ-GîM. Essa instância regional recente reflete o novo papel que esperam desempenhar os municípios na economia política do recurso eólico: reagrupando-se de maneira voluntária, conseguir negociar com grandes promotores acordos de parceria (um pouco) mais generosos ${ }^{16}$. Trata-se, aqui, de uma inovação modesta, mas notável, tendo em vista a estrutura de regulação altamente centralizada, uma vez que a ação coletiva contribui a contrabalançar a concorrência dos territórios locais incitada pelos promotores e a reequilibrar um pouco os poderes presentes. No entanto, a inovação continua bastante limitada, como demonstrado pela fraca integração da variável "paisagem": de forma geral, a iniciativa prolonga a permanência do modelo dominante, com apenas alguns ajustes nos quais a paisagem não é nem considerada. A aposta de renovar os modelos herdados parece assim complexa e sujeita a fortes entraves.

\section{CONCLUSÃO: A PAISAGEM REVELADORA DAS RELAÇÕES SOCIAIS}

"[As] sociedades interpretam seu ambiente em função do ordenamento por elas realizado e, reciprocamente, elas o ordenam em função da interpretação realizada do mesmo" (Berque, 1994, p.17, tradução nossa). Aí está um dos postulados reconhecidos, utilizados em Geografia para ressaltar a ligação entre o mundo reflexivo e o mundo da ação. No entanto, as "paisagens energéticas" questionam essa regra e impõem a consideração da dimensão política, frequentemente oculta, a qual requer ser apreendida em diferentes níveis, do micro ao meso e ao macro.

Claramente, o modelo atualmente dominante é baseado em uma lógica de megaprojetos, os quais privilegiam os grandes atores econômicos, em especial, as grandes corporações. No entanto, o que talvez seja novo é que esse mecanismo gera inúmeros conflitos na época atual. Esses conflitos obrigam o reconhecimento de que os atores sociais estão lutando nos territórios, e são cada vez mais raros aqueles que conseguem fazer valer de forma exclusiva seus pontos de vista e impor suas alternativas de ordenamento. Essas paisagens questionam o poder ou, em outros termos, a capacidade dos atores de modificar a paisagem em suas realidades materiais, em coerência com suas aspirações.

\footnotetext{
${ }^{16}$ Por exemplo, em projetos do tipo "comunitário", os municípios tornaram-se coproprietários dos locais de produção, o que significa a partilha dos lucros gerados pela venda de energia a HydroQuébec, enquanto que eles receberiam apenas "contribuições voluntárias" das empresas privadas em outros tipos de projeto. Notemos que mesmo assim estes projetos ocupam uma parte pequena da produção total, qual seja, cerca de $10 \%$ dos $4000 \mathrm{MW}$ da capacidade prevista instalada.
} 
Essa perspectiva conflitante não facilita a reflexão que liga paisagens e transição energética: em nome dessa transição virtuosa, as paisagens são vistas como ameaçadas por grandes projetos de produção energética, considerados em ruptura com relação às trajetórias históricas e às direções desejadas para os territórios. Todavia, essa rápida leitura negligencia o fato que muitos projetos de produção de energia realmente surgem, às vezes, sem conflitos. Os atores territoriais não são somente um obstáculo "não técnico": a aceitabilidade social continua possível, mas sob uma forma "condicional" ligada às características específicas de um determinado projeto (Wolsink, 2011). Por isso, tanto a forma quanto a essência dos projetos de produção de energia estão em debate: segundo quais modalidades? Por quais interesses? Com quais impactos e para quem? Com quais finalidades?

Essas questões subjacentes aos debates atuais mostram claramente a necessidade de uma mudança no ângulo de análise das paisagens. Os estudos habituais, com foco em dimensões materiais e estéticas, certamente não desaparecerão, sendo especialmente abundantes no contexto de megaprojetos energéticos e de modelos descomedidos: esses megaprojetos estão longe de serem apenas uma marca espacial, na medida em que sua envergadura, física e capitalística, (re)estruturam literalmente estes territórios e suas dinâmicas. Nota-se como os registros do visível e da forma paisagística clássica aparecem insuficientes para apreender essas questões.

Uma possível extensão do roteiro de análise da paisagem consiste em abrir a janela aos processos sociais e econômicos que se desdobram além das formas das paisagens. Ele visa também a unir os esforços intelectuais feitos "aqui e acolá", geralmente relacionados a um ou dois níveis metodológicos, para realizar uma articulação mais sistemática. Esse roteiro pode ser organizado em três escalas de análise concomitantes, cada uma referindo-se a temporalidades próprias em que se manifestariam níveis diferentes de conceitualização da paisagem. 1) O nível das representações da paisagem concerne os processos microssociais de coordenação, de interpretação social e de fabricação de sentido, 2) o nível dos mecanismos institucionais e da paisagem-instrumento toca os processos meso-políticos de deliberação, de construção de compromisso institucional e de regras legítimas, e 3) o nível dos paradigmas e modelos de desenvolvimento se caracteriza pelos processos macroeconômicos de estruturação histórica dos sistemas de produção e de troca, e sua articulação nas trajetórias territoriais.

Por último, mas não menos importante, essa proposta responde a um dos desafios gerados pela transição energética: sua territorialização. A reorientação de nossos modelos de produção e de consumo de energia não podem permanecer no estado de ambições genéricas. Ela exige ser traduzida em políticas públicas, em instrumentos, em projetos e em outras modalidades suscetíveis de gerar a aceitação das populações envolvidas. No entanto, uma condição para sua aceitação é justamente a sua adequação ou sua coerência com as comunidades, seus projetos, territórios e trajetórias específicas. Nesse trabalho laborioso de articulação de interesses e de temporalidades, que se pode designar em termos de aceitabilidade social, estima-se que a paisagem poderia realizar uma contribuição. É necessário, entretanto, considerar com mais vigor a dimensão política, e dessa forma, admitir que a paisagem constitui uma questão de relações sociais contemporâneas, que compreendem o vasto campo da energia e da sua transição. 
Também, talvez, a paisagem poderia ela ser uma maneira de se pensar juntos o futuro do planeta e o de seus territórios?

\section{REFERÊNCIAS}

Bailly, A., "La géographie des représentations : espaces perçus et espaces vécus» dans Les concepts de la géographie humaine, dans Bailly, A. (dir.), Paris, Masson, 1984 , p. 133-138.

Bédard, M. (dir.) Le Paysage, projet politique, Québec, Presses de l'université du Québec, 2009.

Berque, A., "Paysage, milieu, histoire » dans Berque, A. (dir.), Cinq Propositions pour une théorie du paysage, Seyssel, Champ Vallon, 1994, p. 13-29.

Blowers, A., "Nuclear Waste and Landscapes of Risk", Landscape Research, vol. 24 (3), 1999, p. 241-264.

Cosgrove, D. E. "Towards a radical cultural geography: problems of theory", Antipode. A radical Journal of Geography, vol. 15 (1), 1983, p. 1-11.

Cosgrove, D. E., Social formation and symbolic landscape, Madison, Wisconsin, The University of Wisconsin Press, (1984), 1998.

Cosgrove, D. E., "Landscape and the European Sense of Sight - Eyeing Nature », dans Anderson, K, Domosh, M., Pile, S., et Thrift, N. (ed.), Handbook of Cultural geography, Londres, Thousand Oaks, New Delhi, Sage, 2003, p. 249-268.

Creswell, T. "Landscape and the Obliteration of Practice " dans Anderson, K, Domosh, M., Pile, S., et Thrift, N. (ed.), Handbook of Cultural geography, Thousand Oaks, New Delhi, Londres, Sage, 2003, p. 269-281.

Davodeau, H., "L'évaluation du paysage, premier acte des politiques paysagères, Projets de Paysage, 26 juin 2009.

Debardieux, B. et Lardon, S. (dir.), Les Figures du projet territorial, La Tour d'Aigues, Éditions de l'Aube/Datar, coll. "Bibliothèque des territoires », 2003, $270 \mathrm{p}$.

Derioz, P., "L'apparence des choses. Analyser les paysages pour comprendre les systèmes territoriaux », dossier pour l'habilitation à diriger des thèses, 2012, vol. 2.

Dubost, F. et Lizet, B. "Pour une ethnologie du paysage », dans Voisenat, C. (dir.), Paysage au pluriel. Pour une approche ethnologique des paysages, Paris, Éditions de la Maison des sciences de l'homme, coll. "Ethnologie de la France, Cahier $n^{\circ}$ 9, 1995, p. 225-240. 
Evrard, A., "Expliquer le changement par l'interdépendance des temporalités : les politiques de soutien aux énergies renouvelables en Allemagne et au Danemark ", dans Palier B., Surel Y. et al. (dir.), Quand les politiques changent. Temporalités et niveaux de l'action publique, Paris, L'Harmattan, 2010, p. 79-112.

Fortin, M.-J., "Paysage industriel, lieu de médiation sociale et enjeu de développement durable et de justice environnementale: les cas des complexes d'Alcan (Alma, Québec) et de Pechiney (Dunkerque, France) », thèse de doctorat en développement régional (UQAC) et en géographie (Sorbonne-Paris 1), 2005, 541 p., < http://constellation.uqac.ca/535/>

Fortin, M-J et Gagnon, C., "Interpreting Major Industrial Landscapes: Social Follow-up on Meanings, the Case of Two Aluminium Smelters, Alcan (Alma, Québec.) and Pechiney (Dunkerque, France) », Environmental Impact Assessment Review, vol. 26, n8, 2006, p. 725-745.

Fortin, M.-J. Devanne, A.-S. et Le Floch, S., «Le paysage politique pour territorialiser l'action publique et les projets de développement: le cas de l'éolien au Québec », Développement durable et territoires, vol. 1, $\mathrm{n}^{\circ} 2,2010$, $<$ http://developpementdurable.revues.org/8540>

Fortin, M.-J. et Le Floch, S., "Contester les projets éoliens au nom du paysage : le droit de défendre sa cour contre un certain modèle de développement ", Globe: Revue internationale d'études québécoises, vol. 13, n², 2010, p. 27-50. , URL: <http://id.erudit.org/iderudit/1001129ar>

Fortin, M.-J. et Fournis, Y. (dir.) (2013) «Facteurs pour une analyse intégrée de l'acceptabilité sociale selon une perspective de développement territorial: I'industrie du gaz de schiste au Québec », rapport remis au Comité d'ÉES et au MDDEFP, 2013, 185 p.

Fortin, M.-J. et Fournis, Y. (2014) «Vers une définition ascendante de I'acceptabilité sociale: les dynamiques territoriales face aux projets énergétiques au Québec », Natures, sciences et sociétés, 22 : 231-239. En ligne DOI: $10.1051 / \mathrm{nss} / 2014037$

Fournis, Y., Fortin, M.-J., Prémont, M.-C., et Bombenger, P.-H. (avec la coll. de Cossette $S$. et Grondin, A.), « Le sous-secteur éolien et la gouvernance du vent » dans Fournis, Y. et Fortin, M.-J., (dir.), "La transition des régimes de ressources au prisme de la gouvernance : les secteurs forestier, porcin et éolien », rapport remis au comité d'ÉES et au MDDEFP, 2013.

Fournis, Y. et Fortin, M.-J. "Conceptualiser l'acceptabilité sociale : la force d'une notion faible », dans Proulx, M.-U. et Robitaille, M. (dir.), Sciences du territoire, Québec, Presses de I'université du Québec, 2014, t. II, p. 17-33.

Greider, T. et L. Garkovich, 1994, "Landscapes: The Social Construction of Nature and the Environment», in Rural Sociology, Vol. 59, n¹, p. 1-24. 
Guisepelli, E., Miéville-Ott, V., Perron, L., Ros, G. de et Peyrache-Gadeau, $\checkmark$., "Paysage et développement durable: un mariage contre nature? " dans Luginbühl, Y. et Terrasson, D. (coor.), Paysage et développement durable, Versailles, Éditions Quæ, 2013, p. 115-128.

Howlett, M. et Brownsey, K., "Introduction to Special Issue on Canada's Staples Industries », Canadian Political Science Review, vol. 1, n 1, 2007, p. 1-7.

Jenson, J., "'Different' but not 'exceptional': Canada's permeable fordism », Canadian Review of Sociology/Revue canadienne de sociologie, vol. 26, $\mathrm{n}^{\circ} 1$, 1989, p. 69-94.

Jones, M. "The European Landscape Convention and the question of public participation », Landscape Research, vol. 32, n 5, 2007, p. 613-633.

Lelli, L. et Paradis, S. "Analyse critique d'un dispositif méthodologique de diagnostic paysager : le cas du bassin versant du Cérou (Tarn, Midi-Pyrénées) ", Géocarrefour, vol. 80, n² 2, 2005, p. 123-130.

Lewis, J. I. et Wiser, R.H., "Fostering a renewable energy technology industry: An international comparison of wind industry policy support mechanisms », Energy Policy, vol. 35, n³, 2007, p. 1844-1857.

Lipietz, A., "Post-Fordism and Democracy », dans Amin (ed.), Post-Fordism : $A$ Reader, Oxford, Blackwell Publishers Ltd, 1994, p. 338-357.

Lipietz, A., "Géographie culturelle, économique politique et écologie", Géographie, Économie, Société, vol. 2, n², 2000, p. 271-288.

Luginbühl, Y., La Mise en scène du monde. Construction du paysage européen, Paris, CNRS édition, 2013, 432 p.

Luginbühl, Y. et Terrasson, D., Paysage et Développement durable, Versailles, Éditions Quæ, 2013, 311 p.

Michelin, Y., "Des appareils photo jetables au service d'un projet de développement : représentations paysagères et stratégies des acteurs locaux de la montagne thiernoise ", Cybergeo: European Journal of Geography, 7 décembre 1998, < http://www.cybergeo.eu/index5351.html>.

Mitchell, D., "Dead Labor and the Political Economy of Landscape - California Living, California Dying » dans Anderson, K., Domosh, M., Pile, S., et Thrift, N. (ed.), Handbook of Cultural geography, Londres, Sage, 2003, p. 233-248.

Nadaï, A., Werner, K., Afonso, A.I., Dracklé, D., Hinkelbein, O., Labussière, I. et Mendes, C., «Une comparaison de l'émergence de paysages éoliens en France, 
Allemagne et Portugal » dans Luginbühl, Y. et Terrasson, D., Paysage et Développement durable, Versailles, Éditions Quæ, 2013, p. 157- 169.

Netherton, A., "The Political Economy of Canadian Hydroelectricity ", dans Howlett, M. and Brownsey, K. (eds.), Canada's Resource Economy in Transition: The Past, Present, and Future of Canadian Staples Industries, Toronto, Emond Montgomery Publications Limited, 2008, p. 299-329.

Olwig, K. R. et Mitchell, D., " Justice, power and the political landscape: From American space to the European Landscape Convention", Landscape Research, vol. $32, n^{\circ} 5,2007$, p. 525-531.

Paquet, S. et Mercier, G. (dir.), Le Paysage entre art et politique, Québec, Presses de l'université Laval, 2013.

Szarka, J., Wind power in Europe: politics, business and society, Houndmills, Basingstoke, Hampshire ; New York, Palgrave MaCmillan, 2007, 228 p.

Terrasson, D., Berlan-Darqué, M. et Luginbühl, Y. (dir.), De la connaissance des paysages à l'action paysagère, Versailles, Éditions Quæ, 2007.

Warren, C. R., Lumsden, C., O'Dowd, S. et Birnie, R.V., " "Green on green": Public perceptions of wind power in Scotland and Ireland ", Journal of Environmental Planning and Management, vol. 48, $\mathrm{n}^{\circ}$ 6, 2005, p. 853-875.

Wolsink, M. "Wind power and the NIMBY-myth : institutional capacity and the limited significance of public support », Renewable Energy, vol. 21, 2000, p. 4964.

Wolsink, M., "Discourses on the Implementation of Wind Power: Stakeholder Views on Public Engagement » dans Devine-Wright (ed.), Renewable Energy and the Public. From Nimby to participation, Londres, Washington D.C., Earthscan, 2011, p. 75-87.

Submetido em 21/08/2015

Aprovado em 25/10/2015

\section{Sobre a autora}

Marie-José Fortin

Professora na Universidade do Québec em Rimouski e titular da Cátedra de pesquisa do Canadá em desenvolvimento regional e territorial. Com formação em Geografia e Ordenamento do território, suas pesquisas incluem as dinâmicas sociais (conflituosas e de colaboração) e os processos de governança, compreendendo a territorialização de grandes projetos industriais e de produção de energia. Após examinar o processo de implantação de complexos de produção de alumínio, seus trabalhos recentes sobre a energia eólica e o gás de xisto se concentram deste modo em questões atuais, englobando a aceitabilidade social, a governança territorial e a participação cidadã.

Endereço: 300 Allée des Ursulines, Rimouski, QC G5L 3A1, Canadá.

E-mail: marie-jose_fortin@uqar.ca 